\title{
ANTERIOR CERVICAL ARACHNOID CYST WITH SPINAL CORD COMPRESSION
}

\author{
Wuilker Knoner Campos', Marcelo Neves Linhares ${ }^{2,3}$, Irineu May Brodbeck ${ }^{3}$, Iraê Ruhland ${ }^{3}$
}

Anterior cervical arachnoid cysts are rare lesions and despite of the large experience of the departments of neurosurgery worldwide, few cases in this localization have been reported ${ }^{1-7}$. Most intradural arachnoid cysts are located in the thoracic region posterior to the spinal cord $^{1-3,6-8}$.

We present a patient with progressive spinal cord compression caused by an intradural spinal arachnoid cyst that involved to spinal cord ischemic. Ethics committee of the Hospital has approved this case report and the patient's parents gave their informed consent.

\section{CASE}

A 5-year-old girl was hospitalized in a primary hospital without history of trauma with a clinical history of fever, odynophagia, neck pain and rigidity, downcast, reporting that had a superior airway infection on the past week. On the following day, the patient presented left upper extremity palsy, and three days later the palsy reached the rest of the limbs. Despite the radiological and laboratorial exams appeared to be normal, the pediatrician on duty started IV penicillin.

Five days after the first consult, the patient was transferred and admitted in our hospital presenting a regular condition, pallor, hydrated, feverish, tachycardic, with a blood pressure $90 \times 60$ $\mathrm{mmHg}$, intense cervical pain, quadriplegia, sensory deficits in $\mathrm{C} 4$ level, difficulty to speak, hypoventilating, cyanotic and $\mathrm{O}_{2}$ Sat $88 \%$. Due to her respiratory conditions, the patient demanded intubation and intensive care in ICU. The MRI of the cervical spine showed a cerebrospinal fluid (CSF) density lesion located anterior to the cord (intradural) at the upper cervical level and compressing the cord (Figs 1 and 2). Laboratorial exams did not present any alteration.

On the second day the patient was submitted to a posterior arch C1-C2 resection and suboccipital craniectomy with the patient in the prone position. The dura was tense and opening the dura, the spinal cord was tense and bulged into the dural opening. The cyst was opened through excision of cyst membrane. The wall of the cyst was fenestrated into the subarachnoid space and a portion of the cyst wall was taken for biopsy. The patient

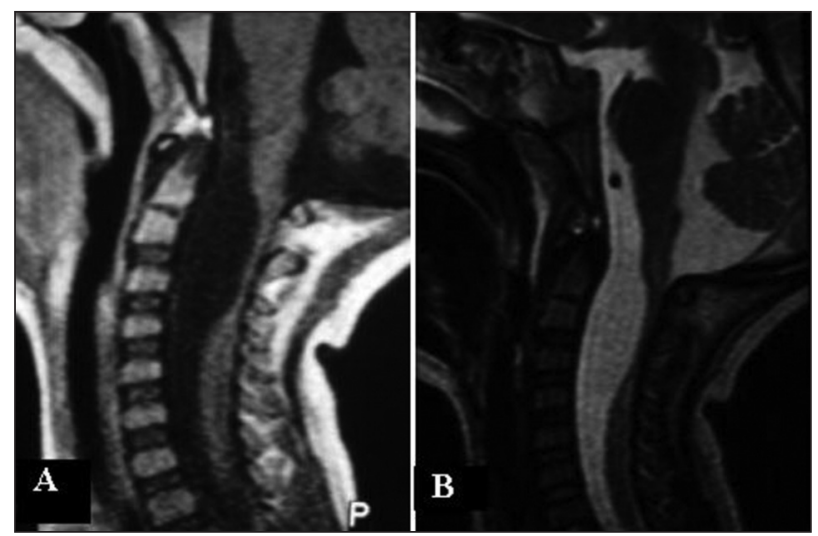

Fig 1. Contrast-enhance sagittal T7-weighted MR image (A) and CTmyelography $(B)$ demonstrates an anterior cyst expanding intraspinally at $\mathrm{C7}-\mathrm{C} 3$. The cyst has same low signal intensity as the CSF on this T7-weighted sequence.
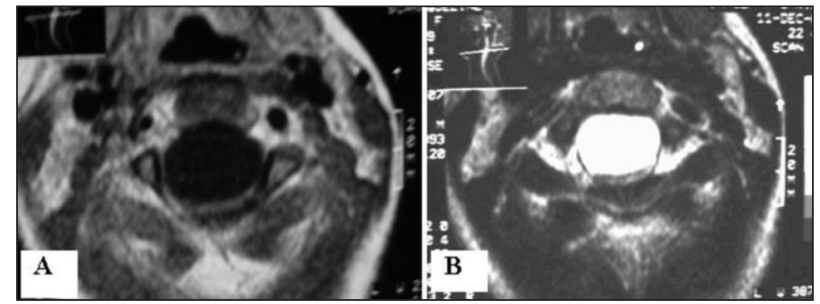

Fig 2. Axial T1-weighted MRI at C2-C3 (A), and CT-myelography at C2-C3 (B) revealing a spinal cord compression.

had respiratory infection in ICU and despite of antibiotic therapy and intensive care, coming to die later by a sepsis shock.

\section{DISCUSSION}

Only 12 cases of intradural arachnoid cysts located anterior to the spinal cord in the cervical region have been reported in the English-language literature to our knowledge. Such cysts have been noted to occur at all levels of the cervical spine. The literature review about intradural anterior cervical arachnoid cysts showed the male-to-female ratio of $4: 1$ and it is also demonstrated to be more frequent in the childhood. The mortality and morbidity

\section{CISTO ARACNÓIDE CERVICAL ANTERIOR COM COMPRESSÃO DE MEDULA}

Departamento de Cirurgia da Universidade Federal de Santa Catarina / Serviço de Neurocirurgia do Hospital Infantil Joana de Gusmão, Florianópolis SC, Brasil: 'Médico Residente em Neurocirurgia; ${ }^{2}$ Professor Doutor; ${ }^{3}$ Neurocirurgião.

Received 6 September 2007, received in final form 5 December 2007. Accepted 6 February 2008.

Dr. Wuilker Knoner Campos - Rua João Pio Duarte Silva 1206 - 88037-001 Florianópolis SC - Brasil. Email: wuilker@yahoo.com.br 
from an arachnoid cyst is not known and depend on the location of the arachnoid cyst and complications, such as acute mass effect by intracystic hemorrhage or the development of a subdural hygroma/hematoma ${ }^{4,6,8,9}$.

Cystic lesions located within the arachnoid membrane may be classified according to the location along the neural axis or by the histological composition of the cyst wall, which is either arachnoid connective tissue or glioependymal tissue. The cysts may be unilocular or loculated by septations. According to the classification of Nabors et al. ${ }^{5}$, the present case is classified as type III, that is, an intradural cyst.

The pathogenesis of arachnoid cysts is unclear, but their congenital origin is usually accepted ${ }^{10}$. A short review of the embryology of the subarachnoid space is necessary for the understanding of the several theories that have been proposed. A loose layer of mesenchymal tissue, called, "perimedullary mesh", surrounds the neural tube in the embryo. It is thought to be the precursor of the pia and arachnoid mater. After the rupture of the rhomboid roof, by the effect of the pulsate force of the choroid plexus, the CSF flows into the layers of the perimedullary mesh. The differentiation of the perimedullary mesh into a superficial layer (the arachnoid mater) and a deeper layer (the pia mater) is the result of the flow of the CSF, causing a duplication of the arachnoid. The development of the arachnoid cysts is thought to be consequence of a minor aberration in the flowing of CSF during the primordial stage of the subarachnoid space, resulting in "sequestration" of an enclosed chamber within the perimedullary mesh.

Several mechanisms could count for the volume increase of these cysts: secretion by the cells forming the cyst walls, unidirectional valve, and liquid movements secondary to pulsations of the veins ${ }^{11}$. It is also postulated that trauma in infancy may contribute to the pathogenesis of arachnoid cysts in some cases ${ }^{10}$, however the precise role of trauma remains unknown. It can also occurs following infectious and chemical meningitis secondary to subarachnoid hemorrhage, subarachnoid adhesions, contrast media, spinal anesthetic agents, spinal surgery and tumor ${ }^{3,12}$.

Most of the cysts are filled with clear fluid of low protein comparable to CSF. Studies about histological examination of the arachnoid cyst wall showed that it is composed of connective tissue containing cells with oval nuclei and a few capillaries, and no inflammatory changes. The adenomatous, cuboidal, columnar epithelial cells with cilia or goblet cell were present. The wall of the cyst is usually smooth and its outer wall adheres weakly to the dura. This wall is composed by blood vessels, and changes of inflammation or hemorrhage seldom occur. The final characterization is based in the intra-operative inspection as much as the histopathological findings ${ }^{13}$.
Spinal arachnoid cysts are usually asymptomatic, but because of the limited size of the spinal canal, the mass effect of these lesions is poorly tolerated and may produce symptoms by compressing the spinal cord or nerve roots suddenly or progressively. The obstruction of CSF pathways due to scarring of the subarachnoid space can also cause symptoms ${ }^{14}$.

The MRI is the imaging modality of choice because is non-invasive, has a superior anatomical visualization and demonstrates the exact location and extent of the cyst. Myelography and CT myelography still have a diagnostic value since they may demonstrate the communication between the subarachnoid space and the cyst.

Conservative management has been proposed for patients who do not demonstrate signs of increased intracranial pressure or focal neurological signs because of the morbidity associated with the surgery". This concept may be true, though controversial, in the case of arachnoid cysts in other locations, but never in cysts located anterior to the spinal cord because of the risk of ischemia. Surgical treatment is necessary if progressive neurological dysfunction appears in the course of spinal cord compression. Several surgical options are possible: direct approach of the cyst, derivation of the cyst with different modalities, or endoscopic fenestration ${ }^{3}$. Complete surgical excision of the cysts is the treatment of choice"

\section{REFERENCES}

1. Aarabi B, Pasternak G, Hurko O, Long DM. Familial intradural arachnoid cysts: report of two cases. J Neurosurg 1979;50:826-829.

2. Alvisi C, Cerisoli M, Giulioni M, Guerra L. Long-term results of surgically treated congenital intradural spinal arachnoid cysts. J Neurosurg 1987;67:333-335.

3. Lesoin F, Leys D, Rousseaux M, et al. Spinal intradural arachnoid cysts. Acta Neurochir (Wien) 1985;76:125-128.

4. Muthukumar N. Anterior cervical arachnoid cyst presenting with traumatic quadriplegia. Childs Nerv Syst 2004;20:757-760.

5. Nabors MW, Pait TG, Byrd EB, et al. Updated assessment and current classification of spinal meningeal cysts. J Neurosurg 1988;68:366-377.

6. Rabb CH, McComb JG, Raffel C, Kennedy JG. Spinal arachnoid cysts in the pediatric age group: an association with neural tube defects. J Neurosurg 1992;77:369-372.

7. Shimizu H, Tominaga T, Takahashi A, Yoshimoto T. Cine magnetic resonance imaging of spinal intradural arachnoid cysts. Neurosurgery 1997;41:95-100.

8. Palmer JJ. Spinal arachnoid cysts: report of six cases. J Neurosurg 1974;41:728-735

9. Kazan S, Ozdemir O, Akyuz M, Tuncer R. Spinal intradural arachnoid cysts located anterior to the cervical spinal cord: report of two cases and review of the literature. J Neurosurg Spine 1999;91:211-215.

10. Choi JU KD. Pathogenesis of arachnoid cyst: congenital or traumatic? Pediatr Neurosurg 1998;29:260-266.

11. Catala M, Poirier J. [Arachnoid cysts: histologic, embryologic and patho physiologic review]. Rev Neurol (Paris) 1998;154:489-501.

12. Agnoli AL, Schonmayr R, Laun A. Intraspinal arachnoid cysts. Acta Neurochir (Wien) 1982;61:291-302.

13. Sato K, Nagata K, Sugita Y. Spinal extradural meningeal cyst: correct radiological and histopathological diagnosis. Neurosurg Focus 2002;13:ecp1.

14. Lee HJ, Cho DY. Symptomatic spinal intradural arachnoid cysts in the pediatric age group: description of three new cases and review of the literature. Pediatr Neurosurg 2001;35:181-187. 